\title{
Publishing Sustainability Research Visually: A Film about the Opportunities and Challenges of a Rural Entrepreneurship Initiative in Kenya
}

\author{
Barry Ness* and Ann Åkerman \\ Lund University Centre for Sustainability Studies (LUCSUS), P.O. Box 170, SE-221 00, Lund, Sweden; \\ E-Mail: barry.ness@lucsus.lu.se; Tel.: +46 462224809 \\ * Corresponding author
}

Submitted: 17 January 2014 | Accepted: 18 February 2014 | Published: 27 February 2014

Keywords: entrepreneurship; film; improved cookstoves; innovation diffusion; Kenya; poverty; rooftop water harvesting systems; sustainability

\section{Knowledge Dissemination and Film}

We have witnessed a large increase in the number of publications on sustainability challenges over the past decade. One important characteristic of the research is with the wide variety of actors that can make use of the results. Sustainability knowledge is often not only relevant for those in academia or policy-making circles, but it can also be useful for decision-makers in a diversity of societal facets and sectors. It is therefore essential that the sustainability research community have access to a diversity of knowledge dissemination outlets, including those that extend beyond the traditional, and often inaccessible, academic publishing realms. One positive development over the past decade in sustainability research reaching broader audiences has been the proliferation of open access publication outlets. The alternative has provided greater access to scientific articles to almost anyone with an Internet connection. But, is this medium of knowledge dissemination sufficient? Are there additional channels that sustainabil- ity researchers can use to broadcast knowledge to even broader user groups?

Another dissemination medium that has developed rapidly, especially since the advent of commercial websites such as Youtube and Vimeo, is film. These platforms have created places for individuals to share information. Despite the rapid growth and great potential of this medium, there are, however, a variety of challenges that must be overcome in using film as an effective form of knowledge transmission in sustainability research. For example, filmmaking skills-such as effectively combining the multiple formats of film clips, photos, narration, and sound-must be developed by researchers in a manner that the film conveys a clear and concise message, is academically rigorous, and, most importantly, holds viewer attention. Furthermore, academic publishing outlets must develop the systems and procedures to meet the demands of film (e.g., DOI numbering, peer review processes, managing large file sizes). 
Video 1: Film on entrepreneurship initiative in Kenya.

\section{Innovation Diffusion in Kenya}

The 18-minute film presented here (Video 1) represents a first small step in uniting open access publishing with a dissemination medium other than the conventional academic article. The film is a part of outreach efforts at the Centre for Sustainability Studies at Lund University to explore and encourage different forms of knowledge to action, especially to those with an interest in poverty alleviation and sustainability in the global South. The film presents the accomplishments and challenges of a rural sustainable development initiative in rural Nyanza Province, Kenya. It focuses on the sale and financing of simple technologies through an entrepreneur. The technologies introduced are improved cook stoves and rooftop water harvesting and storage systems. The film describes the approach, the technologies, and early achievements of the initiative. It then concentrates on the major challenges encountered by the entrepreneur in trying to sustain the initiative throughout the first years of operation, with a special concentration on maintaining the capital to sell additional innovations. The film furthermore addresses solutions to this challenge including the establishment of detailed written contracts, a modest late fee for late payments, a witness to the purchase contract and mobile telephone money transfer options.

The use of film as knowledge dissemination in sustainability research will become more ubiquitous as the obstacles are overcome. There are currently several developments underway including the addition of filmmaking training into educational programs in sustainability, and the creation of new and novel forums for spreading knowledge on sustainability via film. We welcome the developments. 